10 Puska, P, WHO Chronicle, 1973, 27, 55.

11 Puska, P, Publications of the University of Kuopio, Community Health series $A: 1$. Kuopio, University of Kuopio, 1974.

12 Puska, $\mathrm{P}$, in The Promotion of Health: New Trends and Perspectives. Bethesda, Maryland, Van Nostrand Reinhold Co. In press.

${ }^{13}$ Rose, G, and Blackburn, H, Cardiovascular Survey Methods. Geneva, WHO, 1968.

${ }_{14}$ Technicon AutoAnalyzer Methodology N-77. Technicon, 1969.

${ }_{15}$ Carr, J, and Drekter, J, Clinical Chemistry, 1956, 2, 353.

16 Puska, P, Rimpelä, M, and Virtamo, J, Suomen Lääkärilehti, 1972, 27, 2950.

17 Walker, S, and Duncan, D, Biometrika, 1967, 54, 167.

18 Central Statistical Office of Finland, Living Conditions 1950-1975, Statistical Surveys, No 58. Helsinki, Central Statistical Office of Finland, 1977.

19 Farquhar, J, et al, Lancet, 1977, 1, 1195.

${ }^{20}$ Glasunov, I, et al, International fournal of Epidemiology, 1973, 2, 137.

21 Puska, P, et al, Acta Medica Scandinavica, 1978, 204, 381.

22 National Board of Health of Finland, Year Book of National Board of Health 1971-1973, Official Statistics of Finland XI:74. Helsinki, National Board of Health of Finland, 1978.

${ }^{23}$ Tuomilehto, J, et al, International fournal of Health Education, 1978, 21, suppl No 4.

24 World Health Organisation, The Prevention of Coronary Heart Diseases. Copenhagen, Regional Office for Europe, WHO, 1977.

${ }^{25}$ Maccoby, N, et al, fournal of Community Health, 1977, 2, 100.

${ }^{26}$ Schönberger, J, Abstracts of the VIII World Congress of Cardiology, Tokyo, 17-23 September 1978. Tokyo, International Society and Federation of Cardiology, 1978.

27 Tunstall Pedoe, $\mathrm{H}$, et al, Transactions of the European Society of Cardiology, 1978, $1,1$.

${ }^{28}$ Malmros, H, Acta Medica Scandinavica, 1950, 138, suppl.

${ }^{29}$ Levy, R, Preventive Medicine, 1978, 7, 464.
${ }^{30}$ Shimamoto, T, and Komachi, Y, Abstracts of the International Symposium on Essential Hypertension, Herzeg Novi, Yugoslavia, 23-27 October 1978 Belgrade, Federal Executive Council of the SFR Yugoslavia, 1978.

${ }^{31}$ Cooper, R, et al, Abstracts of the VIII World Congress of Cardiology, Tokyo, 17-23 September 1978. Tokyo, International Society and Federation of Cardiology, 1978.

${ }^{32}$ Rimpelä, M, Kansanterveystieteen Laitoksen fulkaisuja, series M:40/78. Tampere, University of Tampere, 1978.

${ }^{33}$ Hyman, H, and Sheatsky, P, Public Opinion Quarterly, 1947, 11, 412.

${ }^{34}$ O'Keefe, T, Public Opinion Quarterly, 1971, 31, 242.

${ }^{35}$ Robertson, L, et al, American fournal of Public Health, 1974, 64, 1071.

36 World Health Organisation, Report on a Working Group on Health Education in Community Control of Cardiovascular Diseases. Geneva, WHO, 1976.

${ }^{37}$ Banks, M, World Smoking and Health, 1978, 3, 39.

${ }^{38}$ Tuomilehto, J, et al, Preventive Medicine, 1978, 7, 539.

${ }^{39}$ Farquhar, J, American fournal of Epidemiology, 1978, 108, 103

${ }^{40}$ Tuomilehto, J, Publications of the University of Kuopio, Community Health, series $A: 2$. Kuopio, University of Kuopio, 1975.

${ }_{11}$ Puska, $\mathrm{P}$, et al, in Childhood Prevention of Atherosclerosis and Hypertension. New York, Raven Press. In press.

42 Report of Inter-Society Commission for Heart Disease, Circulation, 1970, 42, December.

43 World Health Organisation, Methodology of Multifactor Preventive Trials in Ischaemic Heart Disease. Copenhagen, Regional Office for Europe, WHO, 1973.

44 World Health Organisation, The Prevention and Control of Major Cardiovascular Diseases. Copenhagen, Regional Office for Europe, WHO, 1974.

45 Report of a Joint Working Party of the Royal College of Physicians of London and the British Cardiac Society, fournal of the Royal College of Physicians, 1976, 10, 213.

(Accepted 19 September 1979)

\section{Summary and conclusions}

A comprehensive community programme studying the control of cardiovascular diseases (CVD) was carried out in North Karelia, Finland, between 1972 and 1977. The main objective was to reduce the mortality and morbidity of CVD, particularly in middle-aged men. Changes in the mortality and incidence of CVD were monitored by community-based registers of cases of acute myocardial infarction (AMI) and stroke and data on death certificates. During the programme the total mortality in the area decreased by $5 \%$ and the mortality from CVD decreased by $13 \%$ among men and $31 \%$ among women aged 30-64 years. The incidence of AMI fell by $16 \%$ among men and $5 \%$ among women, while that of cerebral stroke fell by $\mathbf{3 8 \%}$ among men and $\mathbf{5 0 \%}$ among women. Changes in mortality in North Karelia

\footnotetext{
Co-ordinating Centre of the North Karelia Project: University of Kuopio, Box 40, 70101 Kuopio 10, Finland, and Epidemiological Research Unit, National Public Health Laboratory, Kuopio JUKKA T SALONEN, MD, special research investigator PEKKA PUSKA, MD, MA, director HARRI MUSTANIEMI, MD, senior physician
}

were compared with those in a matched control area; the difference between the two areas was not significant.

The true effect of the programme cannot be deduced from these results, but mortality from CVD and the incidence of AMI and stroke fell during the five years studied. Thus the changes in mortality and morbidity of CVD accorded with the initial objectives of the programme.

\section{Introduction}

Cardiovascular diseases (CVD) are the main cause of death in middle-aged people, especially men, in most industrialised countries. In many countries-for example, the USA and Finland-the most common manifestation is coronary heart disease (CHD), while elsewhere-for example, Japan-it is cerebrovascular disease. In the early 1970s it was quite obvious that the incidence of CVD varied considerably between countries. The age-standardised mortality from heart disease in men aged $35-64$ years varied from $466 \cdot 8 / 100000$ population in Finland to 73.3 in Japan, and the mortality from cerebrovascular diseases varied from $139 \cdot 6 / 100000$ in Japan to $34 \cdot 7$ in Denmark. ${ }^{1}$

When the World Health Organisation (WHO) started its systematic cardiovascular programme in the 1960 s one of the first tasks was to obtain a more reliable picture of the differences in mortality among countries. Were they true or possibly due only to different national diagnostic or coding practices? In 
addition, further questions were raised concerning, for example, the incidence of non-fatal cases of disease, case fatality rates, and the function of health services in relation to these disease attacks. An international co-operative community-register study of myocardial infarction was launched by the European office of the WHO to answer these questions. The aim of the study was to register in geographically defined pilot areas all possible cases of acute myocardial infarction (AMI) using strictly standardised methods and diagnostic criteria. This study, which was carried out in 1971, confirmed the great differences among countries not only in mortality but also in the incidence of myocardial infarction. The highest incidences were found in the Finnish centres of Helsinki and Tampere. ${ }^{2}$

At the same time another carefully designed study, the sevencountry study, was carried out to investigate the prevalence and incidence of CHD in seven countries in three continents. The results of this study, whose methods differed greatly from the WHO register study, also confirmed these differences among countries and the extremely high rates in Finland. ${ }^{3} \mathrm{~A}$ similar community-register study of cerebrovascular strokes was later launched by the headquarters of the WHO in Geneva. The results confirmed the differences found in mortality between countries. The highest incidences were found in Japan, but the rates were higher in Finland than in other European centres. ${ }^{4}$

These studies all showed that for some years Finland had been suffering from an epidemic of CVD. Statistics and other studies indicated, furthermore, that there were regional differences even within Finland, so that the highest rates were found in eastern Finland, especially in the county of North Karelia. ${ }^{35-8}$ These findings together with growing public awareness and concern led, after a petition from the local population, to the planning and beginning of the North Karelia project. The task of the project was to design and implement a systematic and intensive community-based programme to reduce the incidence of CVD in the whole county and to carry out a scientific evaluation of the programme. The programme was started in 1972, and the first five-year period was evaluated. The main aim of the programme was to control CVD especially by attacking the well-established primary risk factors in the community - that is, smoking, raised serum cholesterol concentration (diet), and raised blood pressure-and by organising systematic treatment, rehabilitation, and secondary prevention for patients with CVD. The main method of implementation was to integrate the activities in the existing health and social services of the area. The programme has been described elsewhere in greater detail. ${ }^{9-12}$

A community programme like the North Karelia project is not static. On the contrary, in every country the health policy and medical services aim at the control of CVD, while secular changes in society may operate through various mechanisms. Thus great interest has been generated recently in the trends in the incidence and mortality of CVD. In a study considering mortality trends in people aged 35-64 in 18 developed countries during 1950-73 an appreciable decrease in mortality from heart disease was found in Canada, USA, Japan, France, Italy, and Portugal. In most (11) of the other countries studied an increase in the age-standardised mortality from heart disease in men was observed. This increase was accounted for mainly by ischaemic heart disease. ${ }^{1}$ In the USA the decrease from 1950 to 1973 in the mortality from heart disease in men aged $35-64$ was $18 \%$.

Recently a decrease of at least $5^{\circ}{ }_{\mathrm{o}}$ in mortality from ischaemic heart disease in men aged 35-74 was noted during 1969-75 in USA, Japan, Australia, Israel, Venezuela, New Zealand, and Canada, and an increase of $5 \%$ or more was found in German Federal Republic, Switzerland, Sweden, France, Eire, Austria, and in most Eastern European countries in men aged 40-69for instance, Poland, Yugoslavia, and Hungary. ${ }^{13}$ The decrease in mortality from CHD in the USA has aroused much interest. Even if this decrease means that the control of CHD in the USA has progressed appreciably the reasons for the development are under debate. ${ }^{13-16}$ Since no community-based registration data are available, it cannot even be said whether this decrease is a result of a decrease in the incidence or case fatality rates, fewer new cases, or improved treatment.

Statistics in Finland show that mortality from CVD and the regional differences in mortality increased rapidly during the 1960 s, but in the beginning of the 1970 s the national mortality rates levelled off. ${ }^{11-19}$ Statistics show that in most countries mortality from CVD decreased from 1950 to 1973 . The decrease in age-standardised rates in people aged 35-64 was, in the USA, $38 \%$ among men and $49 \%$ among women, in Japan $13 \%$ and $50 \%$, and in Finland $6 \%$ and $40 \%$ respectively. ${ }^{1}$

As the objective of the programme in North Karelia-that is, the control of CVD-referred especially to the two major diseases of myocardial infarction and cerebrovascular stroke, myocardial infarction and stroke registers were established in the area at the beginning of the comprehensive programme. The registers served as both information and a means of evaluation.

To evaluate the effect of the programme a matched control area was chosen. This was the county of Kuopio, also in eastern Finland, which was as similar as possible to North Karelia with regard to mortality and morbidity and socioeconomic state. A $6.6 \%$ representative population sample was examined in North Karelia and the control area in 1972, as was another, similar sample in the two areas in 1977, to assess the possible effect of the programme on the risk factors and other related parameters. Community-based registers were not established in the control area, since they were considered to be a part of the intervention in North Karelia. Thus the observed changes in the incidence of myocardial infarction and stroke in North Karelia could be compared with the respective changes in mortality in both areas; as the data become available they will also be compared with respective hospital and health-insurance data. At the end of the five-year period cases of myocardial infarction were registered similarly in the control area for five months.

We aim here to present and analyse the changes in the incidence of CVD and its mortality in North Karelia during the first five years of the intensified community programme, and to relate them to the available data from the control area on changes in mortality and the incidence of myocardial infarction at the end of the period.

\section{Methods}

The system of surveying CVD in North Karelia consists of a register of myocardial infarction, a register of cerebral stroke, and systematic collection of death records in the county medical office. These monitoring methods have been used continuously since the start of the programme and cover the whole county. The myocardial infarction register was started in the area on 1 May 1972. All men and women living in North Karelia in whom AMI is suspected are included in the register as soon as possible, regardless of whether they are alive or dead at the time of registration. The sources for registration are notifications made by doctors; daily records of hospitals, health centres, and outpatient departments; death certificates; and sickness insurance certificates. Almost all patients are treated as inpatients by the central hospital or the wards of the health centres, which helps the registration considerably. Patients still alive are usually registered on the basis of the occurrence of retrosternal pain characteristic of AMI. In some cases, however, pain is not prominent and the clinical picture is dominated by, for example, dyspnoea, sense of suffocation, indigestion, syncope, general malaise, sweating, or acute heart failure. Provided that suspicion of an AMI remains, the case is registered. Laboratory findings also lead to registration in some cases. Information on deaths at which no doctor was present is collected from death certificates.

The AMI register centre is at the Central Hospital of North Karelia, where about two-thirds of all patients with an AMI are treated. The register centre has a full-time register nurse, who collects all the information on the cases using standardised record forms, which are simplified versions of the ones used in the WHO study. Each local health centre nominates one or two of its ward nurses as register nurses, who collect the information on the patients treated 
there for heart attack. The record forms together with complementary medical data are sent to the register centre at the central hospital, where the same doctor reviews the data regularly and decides on the diagnostic classification. The register nurse regularly goes through the death certificates from the area and by other means checks the coverage of the register. She also co-ordinates the primary registration in the area. All the classified record forms are later sent to the coordinating centre of the North Karelia project at the University of Kuopio for data processing and reporting.

According to the criteria of the WHO study ${ }^{2}$ the registered cases are classified by the doctor into the following diagnostic categories: definite AMI, possible AMI, no AMI, and insufficient data. The last category consists of those dead patients in whom AMI as the cause of death can be neither confirmed nor ruled out on the basis of the available information. Fatal cases are considered to be definite AMI when a macroscopic appearance of fresh myocardial infarction or recent coronary occlusion, or both, is found at necropsy; and possible AMI when there is no good evidence for another cause of death and there is a typical history of pain, or no history of pain but evidence of chronic coronary occlusion, stenosis, or old myocardial scarring at necropsy, or clinical evidence of chronic ischaemic heart disease. Fatal cases with no necropsy report, history of pain, history of chronic ischaemic heart disease, or other diagnosis are classified as cases with insufficient data. Among the surviving patients the attack is considered to be definite AMI when there is (a) an electrocardiogram (ECG) showing unequivocal serial changes or (b) a history, typical or atypical, together with an equivocal ECG and raised enzyme concentrations or (c) a typical history and raised enzyme concentrations with either an ECG that shows no changes or no ECG. The attack is classified as possible AMI when the patient has a typical pain but the

\section{MINIPRINT FIGURES $1-6$}
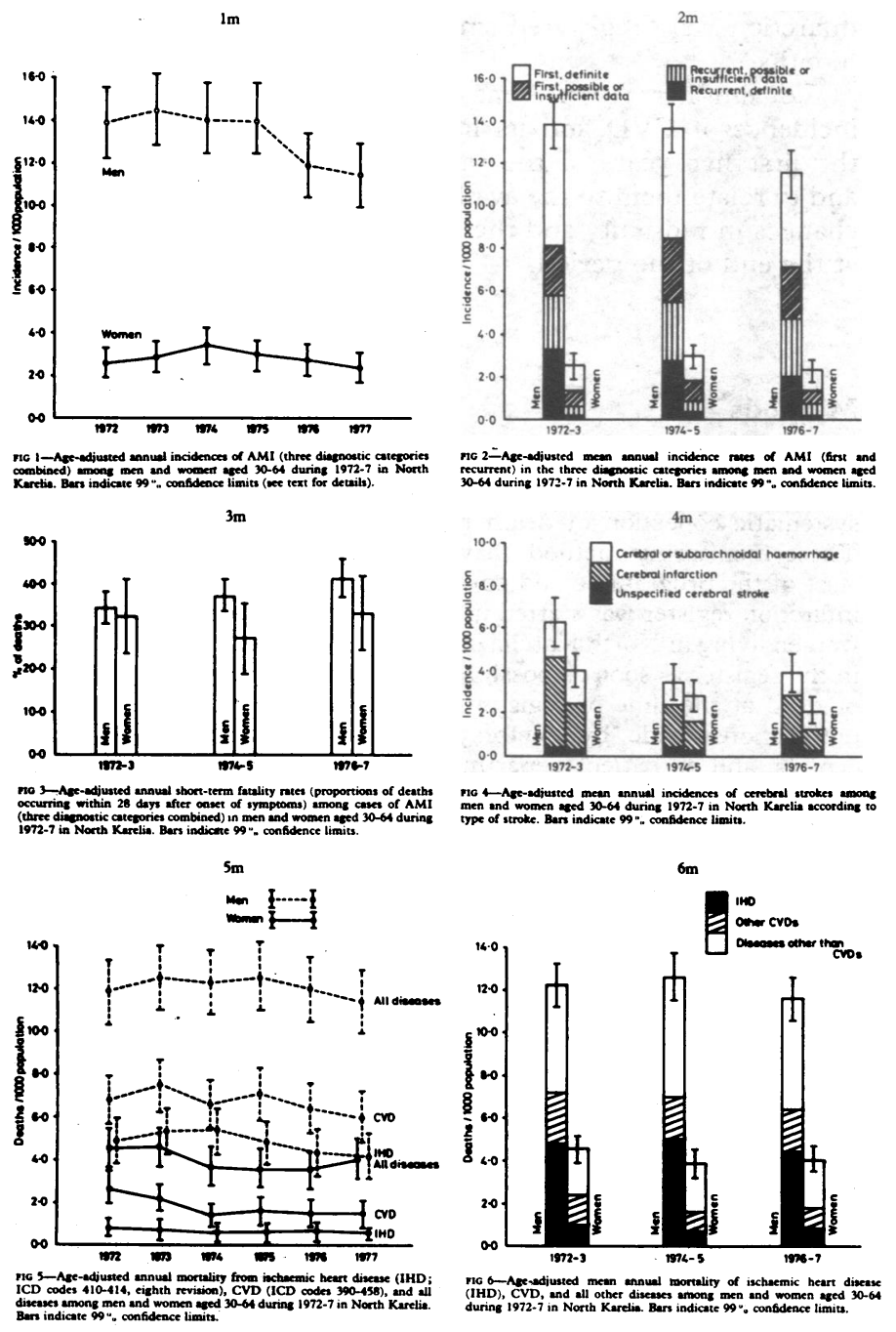

ECG and enzyme results do not place him in the category of definite AMI and there is no good evidence for another diagnosis for the attack; patients are classified as no AMI when there are equivocal ECG changes without a typical history or raised enzyme concentrations, or when chest pain has been explained by another diagnosis.

The ECG classification is made by the same doctor and based on the readings of four records taken one, two, three, and five days after the onset of symptoms of the attack and, if available, records taken before the attack. Criteria for unequivocal ECG changes are (1) the development of a pathological $Q$ wave or (2) the evolution of an injury current (ST change) lasting more than one day, or both. Criteria for equivocal ECG changes are (1) evolution of an injury current that disappears within 24 hours or is present when only one ECG is available; (2) a stationary injury current; (3) symmetrical $T$-wave inversion; (4) bundle-branch block with an additional $Q$ wave; (5) pathological $Q$ wave in a single ECG and no other evidence of development.

To investigate the reliability over time of the diagnostic classification of the cases of heart attack registered a random sample of 30 cases per year was reclassified blind by the doctor who made the initial classification. The degree and significance of agreement between the two classifications were tested by the $x$ statistic proposed by Cohen. ${ }^{21-22}$ Table Im (miniprint) shows the results. There was no significant disagreement between the two classifications either by year or when all cases were considered together.

During the period 1 May to 31 August 1977 cases of AMI in the control area were registered using the same principles and diagnostic criteria as described above. A full-time register nurse registered the cases of heart attack occurring in the central hospital and was in continuous contact with the health centres. Death certificates in the area were checked. The heart attacks were classified by the same doctor who classified cases in North Karelia.

In the same way as described for AMI cases of cerebral stroke in North Karelia was registered as from 1 May 1972, the aim being to register all such cases. The registration still continues. The diagnostic criteria and methods used in registration are those of the WHO co-operative stroke register study, of which our register study was a part. ${ }^{23}$ For registration stroke was defined as rapidly developing clinical signs of focal (or global) disturbance of cerebral function lasting for more than 24 hours or leading to death and having no apparent cause other than its vascular origin. Thus patients presenting with clinical signs and symptoms suggestive of subarachnoid or infracerebral haemorrhage or cerebral ischaemic necrosis are included. By definition transient cerebral ischaemic attacks are not included. The registration and diagnostic classification of stroke are based on clinical diagnosis rather than pathological confirmation. The methods used to register cases of stroke are described in detail elsewhere. ${ }^{23} 24$

All death certificates of the county, which all contain some basic data, are collected at the county health department. These data were further collected by the project and used in the analyses. The classification of the cause of death according to the ICD is based on the original diagnosis of the physician in charge. The possible biases in the diagnoses and in the trends of specific diseases-for example, ischaemic heart disease-are well known. Probably, however, less error occurs in classifying the main disease category - that is, CVDthan would occur if more accurate diagnoses were used.

\section{STATISTICAL METHODS}

The incidence and mortality were calculated for five-year age groups using the number of new events as the numerator and the size of the resident population at the beginning of each year or two-year period as the denominator. The age-adjusted rates were computed using the direct method of standardisation. The population at the beginning of the period was used as the standard. The sampling stability of the estimates of the rates (proportions) was examined by computing their $99 \%$ confidence intervals. Thus the probability that all of the confidence intervals simultaneously covered the true values was more than 0.94 when comparing six rates and more than 0.97 when comparing three rates at the same time. The age-groupspecific variances were calculated by the usual formula for binomial distribution: $\operatorname{Var}\left(R_{i}\right)=R_{i}\left(1-R_{i}\right) / N_{i}$, where $R_{t}$ is the age-specific rate and $N_{1}$ the number of people in the age group.

In comparing the rates in the first and last two-year periods the $95 \%$ confidence intervals of the difference between the two rates were calculated using the square root of the sum of variances of the two rates as the pooled standard error. In addition, each rate was compared separately with the rates in different years by computing 
the difference between two rates. To test the significance of the difference the pooled variances were computed by the formula:

$$
\left.\operatorname{Var}\left(\mathbf{R}_{A}-R_{B}\right)=\Sigma W_{i} R_{(A}+B_{B} i\left(1-R_{(A}+B\right) i\right) /\left(\Sigma W_{i}\right)^{2}
$$

using the weights $W_{1}=N_{A i} N_{B i} /\left(N_{A i}+N_{B i}\right)$ as suggested by Cochran.".; $\mathrm{N}_{\mathrm{Ai}}$ and $\mathrm{N}_{\mathrm{Bi}}$ are the numbers of people in an age group in two areas or at two times that are compared. The approximate standardised normal deviates of the differences were computed by $\left.Z=\left(R_{A}-R_{B}\right) / \sqrt{\operatorname{Var}\left(R_{A}-R_{B}\right.}\right)$, as presented by Armitage. ${ }^{26}$

\section{Results}

According to the AMI register the incidence of all AMIs decreased by $17^{\circ}$ \% from 1972 to 1977 among men aged 30-64 years. Among women there was no consistent trend (fig $1 \mathrm{~m}$ and appendix Im (miniprint)). When only the diagnostic category of definite AMI was considered the reduction in the incidence from 1972 to 1977 among men was even greater, being $18^{\circ}, \mathrm{o}$ for first infarctions and $44^{\circ}, \mathrm{o}$ for recurrent infarctions. Among women there was a reduction of $19^{\circ}{ }_{0}$ in the definite first infarctions and no trend in the other diagnostic categories. Fig $2 \mathrm{~m}$ shows the annual incidences of first and recurrent infarctions by sex and diagnostic category in the three two-year periods (see also appendix IIm). According to the AMI register there was no change in the short-term fatality (28 days after onset) of AMIs from 1972 to 1977 (fig 3m).

From 1972 to 1977 the incidence of all cerebral strokes decreased by $33 \%$ in men and by $35 \%$ in women. When the figures were broken down according to the type of stroke and the comparison based on two-year periods the reduction remained significant for cerebral infarctions, the decrease being $41^{\circ}$, among both men and women (fig $4 \mathrm{~m}$, appendix IIIm).

After the start of the programme there was a reduction in total mortality among all men and women aged 30-64 over the six years studied. In the men this reduction was 6\% from 1972 to 1977 and $11^{\circ} \%$ from 1973 to 1977 , as the rate was increasing during the beginning of the period (fig $5 \mathrm{~m}$, appendix IVm). Cardiovascular mortality also decreased during the period studied. When the comparison was based on two-year periods and done between 1972-3 and 1976-7 the reduction in mortality from CVD among women was $31^{\circ} \%$ (fig $6 \mathrm{~m}$, appendix IVm).

\section{MINIPRINT TABLES}
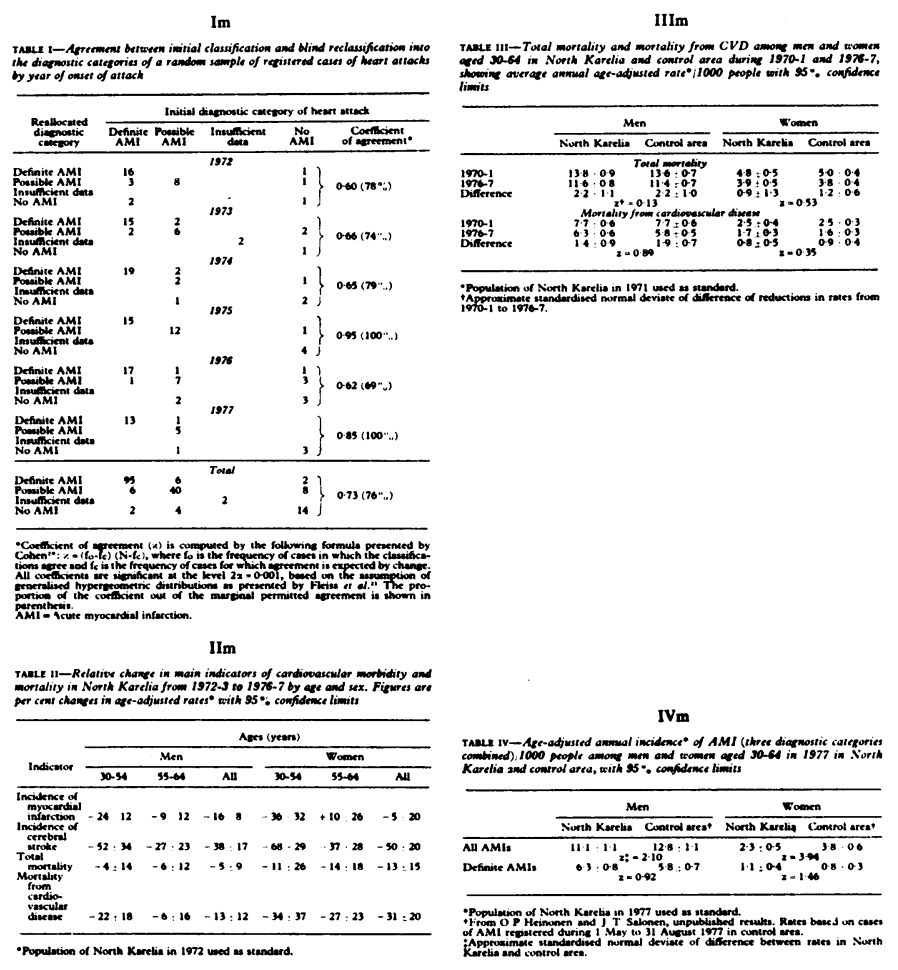

The relative changes in the total incidences of myocardial infarction and cerebral stroke and in the total mortality and mortality from CVD were also calculated separately in two age groups comparing the difference in the rates between the two-year periods 1972-3 and 1976-7. The relative decrease was greater in the younger than the older subjects of both sexes in all indicators of morbidity and mortality except total mortality. The incidence of AMI fell in those aged 30-54 years by $24 \%$ in men and $36 \%$ in women. In the same age group there was a reduction of $52 \%$ in men in the incidence of cerebral strokes; the greatest observed reduction was $63 \%$ in the incidence of cerebral stroke among women aged 30-54 (table IIm). The reduction in mortality from all causes between 1970-1, before the programme began, and 1976-7, the last two years of the programme, was $16 \%$ among men in North Karelia and $17 \%$ in the control area. These differences between North Karelia and the control area, like the differences among women, were not significant. The same applied for mortality from CVD, when the respective figures for men were $18 \%$ and $25 \%$ (table IIIm).

During the five-month period in 1977 when AMI registration was also carried out in the control area the incidence of all AMIs was significantly lower in both men $(11 \cdot 1 v 12 \cdot 8 / 1000)$ and women $(2 \cdot 3 v$ $3 \cdot 8 / 1000$ ) in North Karelia compared with the control area. When only definite AMIs were considered no significant differences were found between the two areas (table IVm).

\section{Discussion}

Monitoring cardiovascular morbidity and mortality in a community has many problems. Examinations of cross-sectional representative samples give little information about the incidence of new cases. A register, even with most complete coverage and rigorous diagnostic criteria, depends on how people with a possible AMI or stroke turn to the health services or are registered. An intensive community programme will probably make people seek medical help more actively and with less severe symptoms than earlier, which would tend to cause a seeming increase in incidences. The finding that definite AMIs decreased more than possible AMIs according to the register in North Karelia indicates that this may have happened in North Karelia, and the real decrease in the incidence of AMI may have been greater than that shown by the register.

Two other problems emerge with a community-based AMI register: maintaining the same diagnostic criteria and the same coverage. In this case the diagnostic criteria were well maintained, as was shown by the blind reclassification. This was mainly because the same doctor made the diagnostic classification throughout the study. The coverage was probably also well maintained, because death certificates and hospital records were checked separately. If the coverage were to decrease this would most likely increase the proportion of definite AMIs, which are the cases that would most easily be registered. This, however, did not happen.

Using mortality data to evaluate a community programme has well-known limitations so far as cause-specific mortality is concerned. This is true especially in areas like North Karelia where necropsy rates are relatively low. The observed rates depend on the doctors' practice of completing the death certificates, which may also change owing to the programme. Age- and sex-specific total mortalities would obviously be the most reliable under these conditions; they are also, however, the most insensitive, because mortality is obviously the last endpoint in the natural course of CVDs, and this is what the programme attempts to change. CVDs cause only a part, albeit a sizable one, of the total mortality.

The problems in monitoring cerebrovascular strokes are the same as those encountered in monitoring AMIs. The diagnostic criteria for a stroke in the register are clinical. Evidence shows, however, that the diagnosis of a stroke as a whole is fairly consistent with the given criteria, but that the subdiagnosis is more unreliable. ${ }^{4}$

The results indicate that morbidity and mortality of CVD decreased in North Karelia during the intervention period. The results suggest that just at the beginning of the programme 
both the mortality and the incidence of AMI were increasing. Among men this increase was reversed firstly in the incidences of AMI and stroke, then in mortalities from CHD and CVD, and lastly in all-cause mortality, which is the logical order. The incidences of AMI and stroke decreased the most, while all-cause mortality decreased the least. The observed reduction in the incidence of AMI among men accords well with the reduction in the CHD risk factors (smoking, serum cholesterol concentration, and blood pressure) among men in the area during the same period. This was found by comparing the results of examinations of representative population samples in 1972 and 1977, and the risk estimate, based on a logistic model and the above-mentioned three risk factors, fell by $17^{\circ}{ }_{0}$ among middle-aged men in North Karelia. ${ }^{12}$

At the start of the programme the CVD mortality and morbidity were much lower among women than among men. During the study no consistent trend was observed in the AMI incidence or mortality among women. A clear reduction was observed, however, in the incidence of stroke. This was obviously reflected in the observed reduction in mortality from CVD.

Regarding a decrease in AMI mortality, the question always remains whether it is due to a reduction in incidence or in case fatality. The latter would suggest improved treatment in the acute phase. This was not, however, the case in North Karelia, where the short-term case fatality remained the same during the period. Thus the reduction in mortality was due to the decrease in incidence. On the other hand, when the figures were broken down for first and recurrent infarctions the reduction in incidence was greater for the recurrent than the first infarctions. This would suggest a considerable contribution of the secondary preventive efforts included in the programme. ${ }^{27}$ This conclusion must be arrived at cautiously, however, because the division between first and recurrent infarctions in the community-based register is in many cases questionable because it is often based only on the history given by the patient.

The considerable reduction in the incidence of stroke in North Karelia occurred among both men and women. The problems of coverage were the same as those for the AMI register. If the reduction is true it is much greater than that in the national trend in mortality from stroke and is most likely to be due to the intensive and obviously successful control of hypertension in the programme; hypertension is a major and well-established risk factor for stroke in North Karelia. ${ }^{28} 29$ In the baseline and terminal surveys it was observed that the proportion of middle-aged people in the area with high blood

\section{MINIPRINTS APPENDICES}

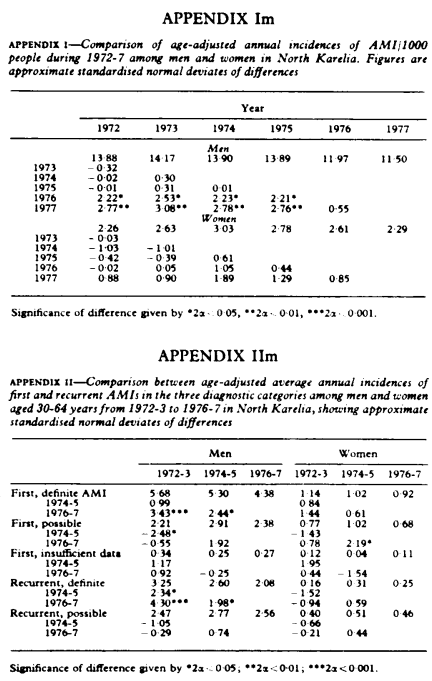

pressure $(\geqslant 175 \mathrm{~mm} \mathrm{Hg}$ systolic or $\geqslant 100 \mathrm{~mm} \mathrm{Hg}$ diastolic, or both) fell by more than $40^{\circ}{ }_{0} .^{12}$

Obviously the CVD mortality and morbidity trends in North Karelia during the intensive community-based programme were decreasing in accordance with the objectives, but the question remains whether this was really caused by the programme. A comparison of the changes in the risk factors in North Karelia with those in the control area showed a highly significant net reduction in North Karelia of the order of $17^{\circ} \%$ for men and $12^{\circ}$, for women. ${ }^{12}$ Thus the programme was probably effective at least with regard to these intermediate objectives. The possible effect of the programme on the main objectives-namely, CVD mortality and morbidity-cannot be stated on the basis of these findings.

During the period when the risk factor levels clearly decreased in North Karelia, only small changes were observed in the AMI risk estimate based on smoking, serum cholesterol concentrations and systolic blood pressure among men in the control area. ${ }^{12}$ This also applied to the estimates of risk of death from CVD and all causes (unpublished observations). Because at the same time, however, there was a reduction in the total mortality and mortality from CVD among men in the control area, it seems that other factors may possibly have been contributing to the decrease in mortality in the control area, and probably in North Karelia as well. This is also supported by the finding that the mortality from CVD started to fall in both North Karelia and the control area around 1970 (unpublished observations).

On the other hand, the intervention programme in North Karelia was built into the community only gradually and the consequent changes in the level of risk factors occured rather slowly during the five-year period. Since an exposure period of decades is probably needed for any individual to develop CVD, obviously the possible effects of such a community programme can be expected only several years after it has been in operation. If the development of other factors affecting the mortality does not differ greatly between the intervention and control areas, the greater reduction in the level of three major risk factors of CVD in the intervention area should be followed by a greater decrease in mortality during the next years. Thus it is essential to carry out a continuing follow-up of morbidity and mortality to assess the further trends.

Requests for reprints should be addressed to Professor Pekka Puska, co-ordinating Centre of the North Karelia Project, University of Kuopio, Box 40, 70101 Kuopio 10, Finland.

\section{References}

${ }^{1}$ Ovcarov, V K, and Bystrova, V A, World Health Statistics Quarterly, 1978, 31, 208.

2 World Health Organisation, Public Health in Europe 5. Copenhagen, WHO, 1976.

${ }^{3}$ Keys, A (editor), American Heart Association Monograph No 29. New York, American Heart Association, 1970

${ }^{4}$ Hatano, S, et al, fapanese Heart fournal, 1977, 18, 171.

5 Puska, P, Suomen Lääkärilehti, 1972, 27, 3071.

6 Puska, P, Aho, K, and Salmi, K, Duodecim, 1974, 90, 965.

7 Puska, P, and Mustaniemi, H, Acta Medica Scandinavica, 1975, 197, 211.

8 Valkonen, T, and Niemi, M-L, Suomen Lääkärilehti, 1978, 33, 1968.

${ }^{9}$ Puska, P, WHO Chronicle, 1973, 27, 55.

${ }_{10}$ Puska, P, Publications of the University of Kuopio, Community Health, series $A: 1$. University of Kuopio, 1974.

11 Puska, $\mathrm{P}$, et al, in Childhood Prevention of Atherosclerosis and Hypertension. New York, Raven Press. In press.

12 Puska, P, et al, British Medical fournal, 1979, 2, 1173.

${ }^{13}$ Havlik, R J, and Feinleib, M, (editors), Proceedings of the Conference on the Decline in Coronary Heart Disease Mortality, National Heart Lung and Blood Institute, Bethesda, Maryland, 24-25 October 1978, NIH Publication No 79-161. US Department of Health, Education, and Welfare, May 1979.

${ }^{14}$ Levy, R, Preventive Medicine, 1978, 7, 464.

${ }_{15}$ Cooper, R, et al, VIII World Congress of Cardiology, Tokyo, 17-23 September, 1978, abstract 0006. Tokyo, International Society and Federation of Cardiology, 1978.

${ }^{16}$ Feinleib, M, Transactions of the European Society of Cardiology, 1979, 1, No 2, abstract 090 . 
17 Leppo, K, Lindgren, J, and Ritamies, M, Yearbook of Population Research in Finland XII, 1971. Helsinki, Population Research Institute, 1972.

18 Puska, P, Hallinto ja Terveys, 1977, 1, 4.

19 Poikolainen, K, Duodecim, 1979, 95, 103

20 Cohen, J, Educational and Psychological Measurement, 1960, 20, 37.

${ }^{21}$ Fleiss, J L, Cohen, J, and Everitt, B S, Psychological Bulletin, 1969, 72, 323.

22 Fleiss, J L, Psychological Bulletin, 1971, 76, 378.

${ }^{23}$ Hatano, S, WHO Bulletin, 1976, 54, 541.

24 World Health Organisation, Community Control of Stroke and Hypertension, report of a WHO meeting, Gothenburg, 29 November3 December 1971, WHO (CVD/72 1). Geneva, WHO, 1972.
${ }^{25}$ Cochran, W G, Biometrics, 1954, 10, 417.

${ }^{26}$ Armitage, P, Statistical Methods in Medical Research. Oxford, Blackwell Scientific Publications, 1971.

27 Salonen, J T, and Puska, P, Scandinavian fournal of Rehabilitation Medicine. In press.

28 Salonen, J T, et al, to be published.

29 Tuomilehto, J, et al, Current Concepts of Cardiovascular Diseases-Noninvasive Diagnosis, ed E B Dietriech. Baltimore, Baltimore University Park Press. In press.

\title{
Maternal perception of fetal motor activity
}

\author{
KEITH HERTOGS, ALISTAIR B ROBERTS, DEREK COOPER， DAVID R GRIFFIN, \\ STUART CAMPBELL
}

British Medical fournal, 1979, 2, 1183-1185

\section{Summary and conclusions}

A technique using real-time ultrasound for comprehensive recording of fetal motor activity was used in 20 subjects in the third trimester of pregnancy. Maternal awareness of fetal movement correlated with the number of fetal parts contributing to the movement but not with maternal parity or obesity, gestational age, placental site, or duration of the fetal movement. Some subjects recorded fetal breathing, passive fetal displacement, and Braxton Hicks's contractions as fetal movement. Most of our subjects were consistent and accurate in their perception of major fetal movements, but a few were inconsistent and one was completely unaware of major fetal movements.

These results suggest that kick counts kept by most mothers will be accurate. Low counts of fetal movement should be an indication for fetal monitoring by other means and not, unconfirmed, for intervention.

\section{Introduction}

Maternal awareness of decreased fetal activity is a sign of fetal hypoxia. ${ }^{1-3}$ The number $\mathrm{r}^{12}{ }^{4}$ and intensity ${ }^{5}$ of fetal movements decrease with deteriorating fetal condition. When movements disappear altogether, 12-48 hours before fetal death, ${ }^{2}{ }^{4}$ the fetal cardiotocograph is already abnormal. ${ }^{6}$ The mother's record of the daily count of fetal movements is a more specific indicator of fetal compromise than serial urinary oestrogen measurements. ${ }^{2}$ Cheapness and simplicity make the kick count a globally useful method of fetal monitoring. Sadovsky and Yaffe $^{1}$ and Pearson ${ }^{7}$ anticipated that maternal perception of fetal movement might show subjective variation. Objective methods of assessing fetal movement including palpation by an observer ${ }^{8}$ and using a strain gauge, ${ }^{8}$ a tocodynamometer, ${ }^{9}$ an electromagnetic re-

\footnotetext{
Department of Obstetrics and Gynaecology and Computer Unit, King's College Hospital Medical School, London SE5 8RX

KEITH HERTOGS, MB, senior house officer

ALISTAIR B ROBERTS, MRCOG, research fellow

DEREK COOPER, MSC, PHD, senior analyst

DAVID R GRIFFIN, MRCOG, research fellow

STUART CAMPBELL, FRCOG, professor
}

corder, ${ }^{10}$ and an impedance plethysmograph ${ }^{4}$ have been reported as showing good agreement with maternal counts of fetal movement. Using real-time ultrasound Gettinger et al ${ }^{11}$ were the first to question the sensitivity of these methods. A mean of $57^{\circ}{ }^{\circ}$ of fetal movements detected by ultrasound were not perceived by their subjects, who showed a wide range of sensitivity to fetal movement. This finding does not question the value of kick counts, provided that each mother has a constant sensitivity to the movements of her fetus.

This study was designed to investigate further the kick count. We describe a technique for comprehensively observing the fetus using real-time ultrasound, which we used to record movements of all fetal parts and to determine which physical variables influenced maternal perception. We then assessed our subjects' consistency at detecting fetal movement during three periods of observation.

\section{Subjects and methods}

We studied 20 pregnant women between 32 and 43 weeks' gestation. They were all used to recording fetal movements. Obstetric complications included diabetes mellitus (six cases), hypertension (three), cervical cerclage (three), intrauterine growth retardation (two), placenta praevia (two), postmaturity (one), mitral valve disease (one), and chronic bronchitis (one). There was one normal pregnancy. Ultrasound examination was performed using two real-time scanners. The subject lay semi-recumbent, with a pillow under her right side, to prevent supine hypotension. The transducers were held in place with universal clamps. One transducer recorded cross-sections of the fetal head and arms, the other of trunk and legs. Views of trunk, head, and at least one arm and one leg were obtained in all sessions. We tried to view all four limbs continuously, but this was not always possible: arms particularly moved out of the picture, and the posterior leg was sometimes hidden in acoustic shadow.

We studied 10 subjects for a single 30 -minute session and 10 for three 30-minute sessions at weekly intervals. Fetal hiccoughs occurred during four sessions. The importance of fetal hiccoughs is not known, ${ }^{11}$ but subjects always perceived them as a series of kicks, giving high counts of movement. We abandoned the sessions in which fetal hiccoughs occurred and repeated them later. Many subjects recorded Braxton Hicks's contractions as movements. We therefore specifically ascertained that subjects could differentiate contractions from movements, and asked them to ignore contractions. Apart from this, subjects decided for themselves what constituted a fetal movement and recorded the start and end of each movement using a hand-held recorder attached to a computer-tape punch. The ultrasound images were simultaneously videotaped. Television monitors were placed outside the subjects' field of vision. The start of the video recording was carefully synchronised with that of the subject's observation period.

The videotapes were later analysed by one of us, the beginning and 